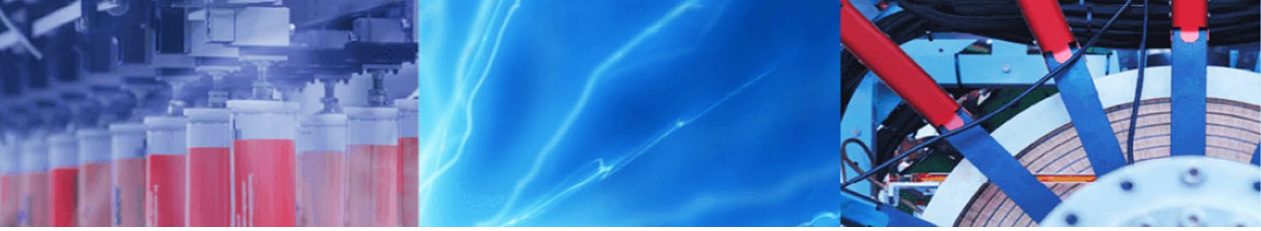

Research Article

\title{
The effect of solvent on the mechanical properties of polyhedral oligomeric silsesquioxane (POSS)-epoxy nanocomposites
}

\author{
Kunal Mishra ${ }^{1}$ (1) $\cdot$ Libin K. Babu' ${ }^{1}$ Dilli Dhakal ${ }^{2} \cdot$ Pralhad Lamichhane $^{2} \cdot$ Ranji K. Vaidyanathan $^{2}$
}

(c) Springer Nature Switzerland AG 2019

\begin{abstract}
The present study investigated the influence of different compatibilizer on the dispersion of polyhedral oligomeric silsesquioxane (POSS). The effect of POSS dispersion in the epoxy resin in terms of mechanical, and thermal properties were reported. The three solvent used to disperse POSS in this work are ethanol, acetone, and toluene. The POSS was initially dispersed in the solvent followed by an addition in the epoxy resin by systematically varying the weight fraction from 0.5 to $8 \mathrm{wt} \%$. Mechanical properties of nanocomposites were characterized in terms of elastic modulus, and fracture toughness. The obtained result illustrates that nanocomposites prepared by polar solvent dispersion such as ethanol showed an increase in values of elastic modulus and fracture toughness value. The increase in the modulus and fracture toughness value is due to the better interaction between POSS and ethanol disperse the POSS uniformly in the epoxy resin while avoiding the agglomeration. However, nanocomposites prepared by nonpolar solvent does not show substantial change in the mechanical properties. Fractured surface morphology was studied using scanning electron microscopy. Differential scanning calorimetry and dynamic mechanical analysis illustrates that with better POSS dispersion value of glass transition temperature $\left(T_{g}\right)$ increased. Fourier transformation infrared spectroscopy showed that POSS completely interacted with the epoxy resin and no phase separation was observed.
\end{abstract}

Keywords POSS · Solvent · Fracture toughness · Elastic modulus · DMA · SEM

\section{Introduction}

Thermosetting polymers such as epoxy resin exhibit low values of fracture toughness and strain to failure due to their high crosslinking. To increase the fracture toughness, common approach is to add fillers that lead to extrinsic toughening mechanisms. A considerable amount of work has been done to enhance the fracture properties of the resin by introducing a second phase as a reinforcement. Various fillers, such as rubber particles [1], metal particles $[2,3]$, layered silicates [4-6], carbon nanofibers [7], carbon nanotubes (CNT) [8, 9], graphene [10], and block copolymers $[11,12]$ have been used with varying degree of success. However, these nanofillers tend to form agglomerates that can become a critical site of failure which results in deterioration of the properties. Therefore, various investigation have been done in dispersing these nanofillers using different processing techniques to optimize the properties of such nanocomposites [13-17].

Various studies have been done in the past to combine the advantage of organic (flexibility, reactivity, and processability) and inorganic fillers (rigidity, high stability) by developing hybrid materials $[18,19]$. Polyhedral oligomeric silsesquioxane (POSS) is hybrid material made up of organic-inorganic monomer silsesquioxane $\left(\mathrm{RSiO}_{1.5}\right)$. The POSS molecule has a size of 1-3 $\mathrm{nm}$ and possesses an inorganic rigid cage type structure containing silicon and oxygen, and selectable organic groups (R) attached to the silicon atoms. The advantage of using POSS is that it offers the selection of the organic group (R) based on

Ranji K. Vaidyanathan, vaidyan@okstate.com | 'School of Mechanical and Aerospace Engineering, Oklahoma State University, Stillwater, OK 74078, USA. ${ }^{2}$ School of Material Science and Engineering, Oklahoma State University, Tulsa, OK 74106, USA.

SN Applied Sciences (2019) 1:898 | https://doi.org/10.1007/s42452-019-0918-1

Received: 16 May 2019 / Accepted: 11 July 2019 / Published online: 23 July 2019 
the requirement. POSS can interact with the polymer in two ways, either by forming covalent bonds or POSS can show compatibility either by similarities in chemical structure or by the specific polar interaction between non-reactive organic groups on the POSS molecule and the epoxy polymer chain. There have been extensive studies on the formation of POSS as reinforcement, or formation of nanoscale structure to modify the mechanical and thermal behavior [20-29]. In our previous work, we have reinforced epoxy resin with the POSS molecule, and we have observed that based on a compatible POSS molecule, the fracture toughness increases by $200 \%$ compared to the neat resin at room temperature $[16,30]$ or at cryogenic conditions [31]. It is generally believed that the quality of POSS dispersion in the epoxy resin is directly correlated to its efficiency in the improvement of mechanical, electrical and thermal properties.

Therefore, it would be interesting to investigate the toughening mechanism of POSS-epoxy nanocomposites and influence of POSS molecule as a function of dispersion in a solvent, and weight fraction. As far as we know, there are no studies to date report on the effect of solvent on the properties of POSS-epoxy nanocomposites.

\section{Materials and methods}

The polymer system selected for this study is diglycidyl ether of bisphenol-F based resin (EPON 862, Hexion Specialty Chemicals, Columbus, $\mathrm{OH}$ ), cured with a low viscous aliphatic amine (EPIKURE 3274, Hexion Specialty Chemicals, Columbus, $\mathrm{OH}$ ).

Both the resin and the curing agent were acquired from Miller-Stephenson Chemical Company, (Danbury, $\mathrm{CT}$ ). This epoxy resin system is a highly cross-linked network that results in excellent mechanical properties and high chemical resistance. The reason behind the selection of this epoxy resins was their superior mechanical properties, easy handling and also these resins are very well studied in the literature. The POSS selected in this work is trisilanol phenyl POSS (Hybrid Plastics, Hattiesburg, MS), organic phenyl groups attached at the corners of the cage with three active silanol functionalities. POSS can confirm compatibility with epoxy resin through hydrogen bonding, a similar chemical structure, and $\pi-\pi$ interaction. Three different solvents have been used in this work, two solvents selected in this work are based on the polarity, ethanol (polar) and acetone (non-polar) and with compatibility, toluene. All three solvents were acquired from Sigma Aldrich (St. Louis, MO). The solvents were first mixed with POSS by using ultrasonication (TM750, Tekmar-Dhormann, Cincinnati, $\mathrm{OH})$, operating at $20 \mathrm{kHz}$ frequency with $5 \mathrm{~s}$ on-off cycle, for $15 \mathrm{~min}$. It was followed by mixing of
POSS-solvent solution in the epoxy resin for $12 \mathrm{~h}$ at $70^{\circ} \mathrm{C}$ and $200 \mathrm{rpm}$ on a magnetic stirrer (VWR Advanced Hot Plate Stirrers, Sugar Land, TX).

A stoichiometric amount of amine-based curing agent was added by 40 wt $\%$ of epoxy and gently mixed with the hand to avoid excessive introduction of air bubble introduced during mixing. The mixture was then placed in a vacuum chamber for $30 \mathrm{~min}$ for degassing, to remove trapped air bubbles. Finally, the liquid mixture was poured into a pre-prepared aluminum mold. The degassed mixture was poured into a pre-prepared mold for casting and cured at room temperature for $24 \mathrm{~h}$. The cast plate was then released from the mold and post cured at $121^{\circ} \mathrm{C}$ for $6 \mathrm{~h}$. Materials were fabricated with TSP POSS at loading levels of $0.5 \%, 1 \%, 3 \%, 5 \%$, and $8 \%$ with respect to epoxy resin. The same curing cycle was used for preparing neat resin as a baseline material.

\section{Characterization}

Fracture toughness was determined by performing a single edge notch bend test as per ASTM D-5045 [32]. Samples were machined from the cast plate in the nominal dimensions of $54.0 \mathrm{~mm} * 12.7 \mathrm{~mm} * 6.3 \mathrm{~mm}$. A $4.5 \mathrm{~mm}$ deep notch was cut using a diamond precision saw (MK370, MK Diamond Products Inc., Torrance, CA). Then the tip of the notch was tapped lightly with a fresh razor blade using a hammer to initiate a natural pre-crack. The nominal crack length was kept between 5.7 and $6.9 \mathrm{~mm}$ to maintain as a/W ratio of $0.45-0.55$ as per the ASTM standard. The precracked single edge notch specimens were loaded under three-point bending using a universal testing machine (Instron 5567, Norwood, MA). The fracture toughness of nanocomposites were measured in terms of critical stress intensity factor $\left(K_{I C}\right)$ calculated from the peak load $(P)$, as per the ASTM standard [32].

The elastic modulus of the nanocomposites was determined as per ASTM D-638 [33]. Samples were machined from cast plate with nominal dimension for Type 1 specimen (thickness less than $7 \mathrm{~mm}$ ) as per the ASTM standard. Extensometer was set within the gauge length to register the actual change in distance between two points when the specimen is pulled. Tests were conducted in the displacement-controlled mode at a fixed crosshead speed of $0.1 \mathrm{~mm} / \mathrm{min}$ till the specimen failure. The elastic modulus was determined from the stress-strain curve.

Dynamic mechanical analysis (DMA) were done on the POSS-epoxy nanocomposite using TA Instruments DMA Q800 (TA Instruments, Inc., New Castle, DE). A sample of size $60 \mathrm{~mm} * 12.7 \mathrm{~mm} * 3 \mathrm{~mm}$ was prepared and placed in a dual-cantilever clamping mode, with a span length of $35 \mathrm{~mm}$. Three-point bending test was carried 
out simultaneously with heating the sample from $30^{\circ} \mathrm{C}$ to $200{ }^{\circ} \mathrm{C}$ at $3{ }^{\circ} \mathrm{C} / \mathrm{min}$, and by applying a constant sinusoidal displacement of $20 \mu \mathrm{m}$ with $1 \mathrm{~Hz}$ frequency. The storage modulus, loss modulus and damping factor $(\tan \delta)$ were obtained from the sample response against applied frequency. Thermal analysis of samples was carried out using the differential scanning calorimeter (Q 2000 DSC, TA Instruments, Inc., New Castle, DE). Approximately 5-10 mg of sample was loaded in an aluminum pan. To study the glass transition temperature $\left(T_{g}\right)$, the samples were initially heated to $210^{\circ} \mathrm{C}$ at a scan rate of $15^{\circ} \mathrm{C} / \mathrm{min}$, held at that temperature for 2 min to eliminate any previous thermal history, and then cooled to $-25^{\circ} \mathrm{C}$ at a cooling rate of $15^{\circ} \mathrm{C} / \mathrm{min}$. For the second scan, the samples were heated and cooled under the same conditions. The glass transition temperature data has extracted from the second heating cycle.

Fourier transform infrared (FTIR) spectroscopy was performed to investigate the chemical interaction between POSS and epoxy. POSS-epoxy nanocomposite powder was added to $\mathrm{KBr}$ in the ratio of 1 part of the sample to 99 parts of $\mathrm{KBr}$. These powdered samples were loaded in an FTIR spectrometer (Nicolet iS10, Waltham, MA) and subjected to 128 scans at a resolution of $4.0 \mathrm{~cm}^{-1}$. The spectrum was collected at room temperature between 4000 and $500 \mathrm{~cm}^{-1}$.

The fractured surface was studied using a field emission scanning electron microscopy (Hitachi S-4800 FESEM, Dallas, TX). The surfaces of the samples were coated with gold by an electro-deposition method using a sputter coater (Cressington Scientific Instruments Ltd, Redding, CA).

\section{Results and discussion}

\subsection{Fracture toughness}

Figure 1 shows the variations in the fracture toughness of POSS-epoxy nanocomposites as a function of POSS loading as well as the type of solvent used for the dispersion. We observed that for all the specimen the fracture toughness increases with the POSS loading attains, the maximum followed by a decrease in the toughness value.

As result indicates, at low weight fractions of POSS inclusion, the fracture toughness value for all the specimen is equivalent. However, at higher POSS loading, the influence of the dispersion of POSS is there is a pronounced impact on the fracture toughness based on the type of solvent used. From the result, as shown in Fig. 1, we observed that use of ethanol and acetone as dispersion medium leads to the increase in fracture toughness by $60 \%$ and $80 \%$ at 3 and 5 wt $\%$ respectively. It must be noted that for epoxy/ POSS/Acetone the fracture toughness attains a maximum

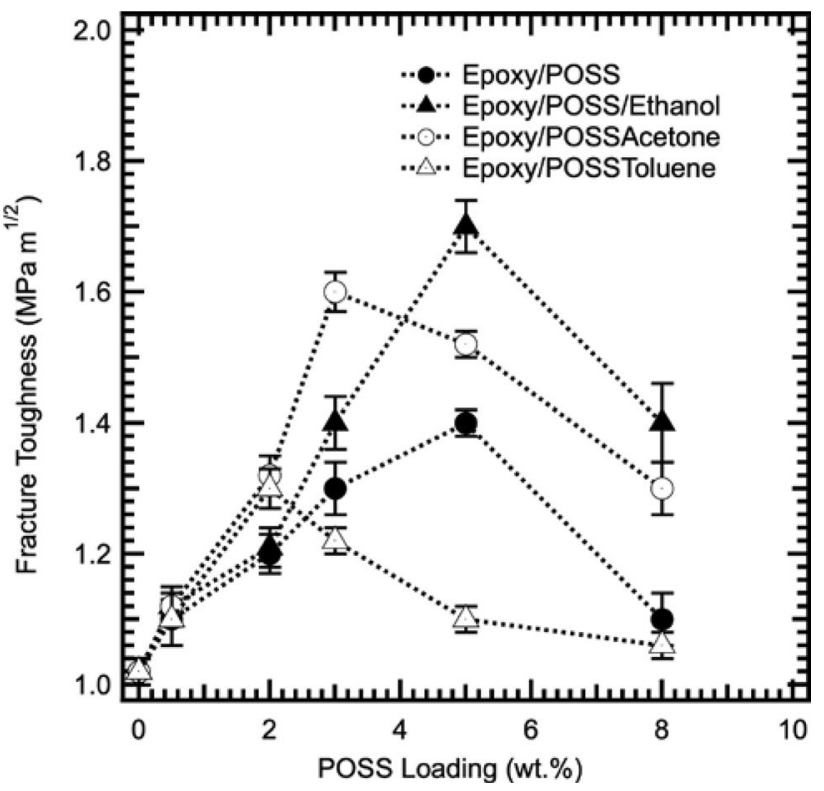

Fig. 1 Effect of different solvents on the fracture toughness of the POSS-epoxy nanocomposites

at 3 wt $\%$ while for epoxy/POSS/ethanol the maximum fracture value achieved at $5 \mathrm{wt} \%$, this suggests that presence of a polar solvent such as ethanol provides the better dispersion of POSS. This is due to the presence of $-\mathrm{OH}$ group present in silica cage forming hydrogen bond with the ethanol, which leads to the better distribution of POSS at higher loading. After attaining the maximum value, the fracture toughness of the epoxy/POSS/ethanol and epoxy/POSS/acetone decreases. This decrease in the fracture toughness value is due to the formation of POSS agglomerates that deteriorates the material. The formation of POSS agglomerates and its influence on the mechanical properties are explained in detail in our previous work [30, 31]. The nanocomposite prepared without solvent shows an increase in the fracture toughness by $40 \%$ at $5 \mathrm{wt} \%$. However, epoxy/POSS/toluene exhibit a decrease in the fracture toughness value after attaining the maximum value of $30 \%$ at $3 \mathrm{wt} \%$ followed by a decline in the value. The presence of bigger size benzene group in the POSS and the toluene cause the steric hindrance hence leads to the formation of agglomerates at higher POSS loading.

\subsection{Elastic modulus}

Figure 2 shows the influence of solvent and POSS loading on the elastic modulus of the nanocomposite. The elastic modulus values increase as a function of POSS loading up to a specific value and after that decrease with the further addition of POSS. The decrease in modulus value at higher values of POSS loading can be attributed to agglomeration 


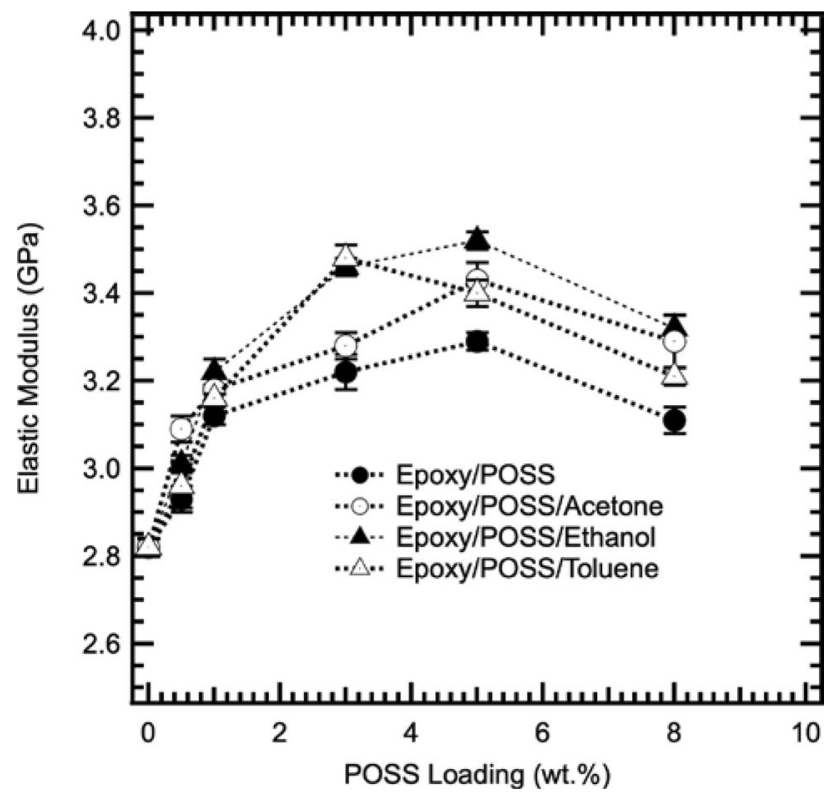

Fig. 2 Effect of different solvents on the elastic modulus of the POSS-epoxy nanocomposites

of the POSS molecules. For the epoxy/POSS nanocomposites, we observed the increase by $14 \%$ at 5 wt $\%$.

Epoxy/POSS/ethanol exhibit an increase by $25 \%$ at $5 \mathrm{wt} \%$, this increase in the elastic modulus value is due to the similar phenomenon explained in the previous section. Epoxy/POSS/Acetone and epoxy/POSS/Toluene shows maximum elastic modulus value by $23 \%$ and $21 \%$ at $3 \mathrm{wt} \%$ and $5 \mathrm{wt} \%$ respectively. It must be interesting to note that the increase in the elastic modulus value does not depend on the type of solvent, unlike the fracture toughness observation.

\subsection{FTIR}

To understand the POSS-epoxy interaction and the role of solvent, FTIR spectroscopy was performed as shown in Fig. 3. The broad peak from 3500 to $3100 \mathrm{~cm}^{-1}$ represents the $-\mathrm{OH}$ stretching, which indicates the polymerization of the epoxy resin. The presence of the peak at $1110 \mathrm{~cm}^{-1}$ corresponds to $\mathrm{Si}-\mathrm{O}-\mathrm{Si}$ stretching suggest that POSS has been entirely absorbed by epoxy resin. The medium peak around $1400 \mathrm{~cm}^{-1}$ for the neat resin suggested the presence of -OH bending, however, with the inclusion of POSS molecule the peak at $1400 \mathrm{~cm}^{-1}$ diminishes indicates the formation of covalent bond due to the reaction between POSS and epoxy resin. More interestingly peak of the constitutive solvent was not observed, indicating that the solvents (ethanol, acetone, and toluene) were evaporated during the curing process.

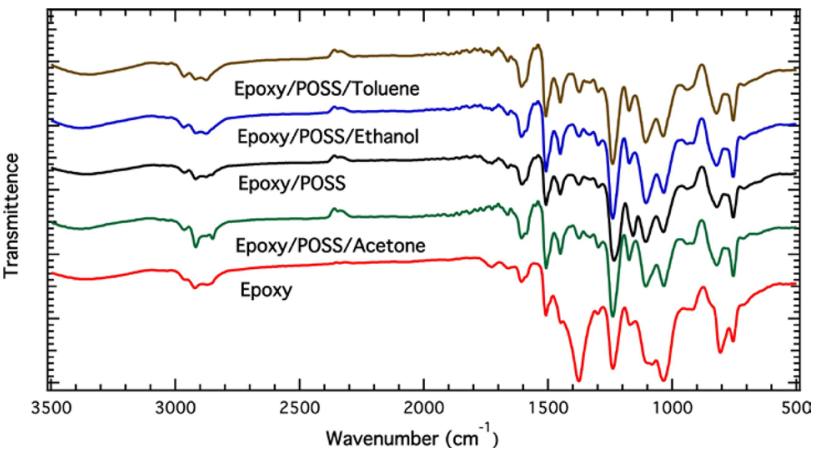

Fig. 3 FTIR spectra of neat resin and 5 wt\% POSS/epoxy nanocomposite fabricated by different dispersion technique

\subsection{Dynamic mechanical analysis (DMA)}

Figure 4 illustrates that the storage modulus value of the nanocomposites does not change with the inclusion of the POSS molecule. For epoxy/POSS/ethanol nanocomposites we observed the increase in modulus value at glassy state as well as in rubber state. The result indicates that the proper dispersion of POSS molecule leads to the rise in the storage modulus value. The obtained result corroborates with the result obtained from elastic modulus and fracture toughness experiment.

The loss modulus value represents the energy dissipated due to molecular friction. We observed that the inclusion of the POSS molecule does not change the loss modulus value. However, we noted that with better

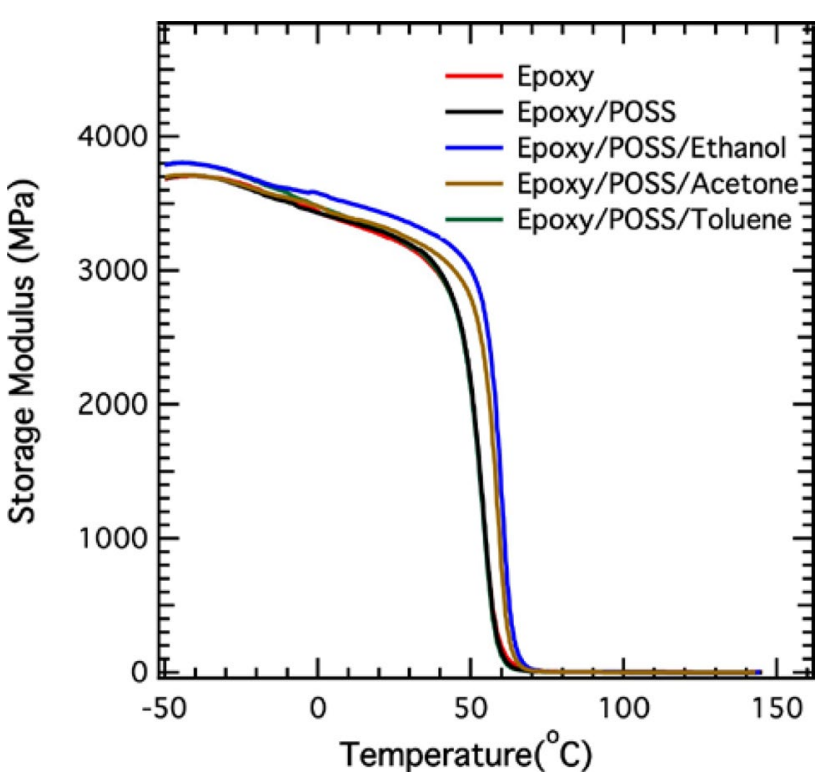

Fig. 4 Storage modulus curve of neat resin and 5 wt\% POSS/epoxy nanocomposite fabricated by different dispersion technique 


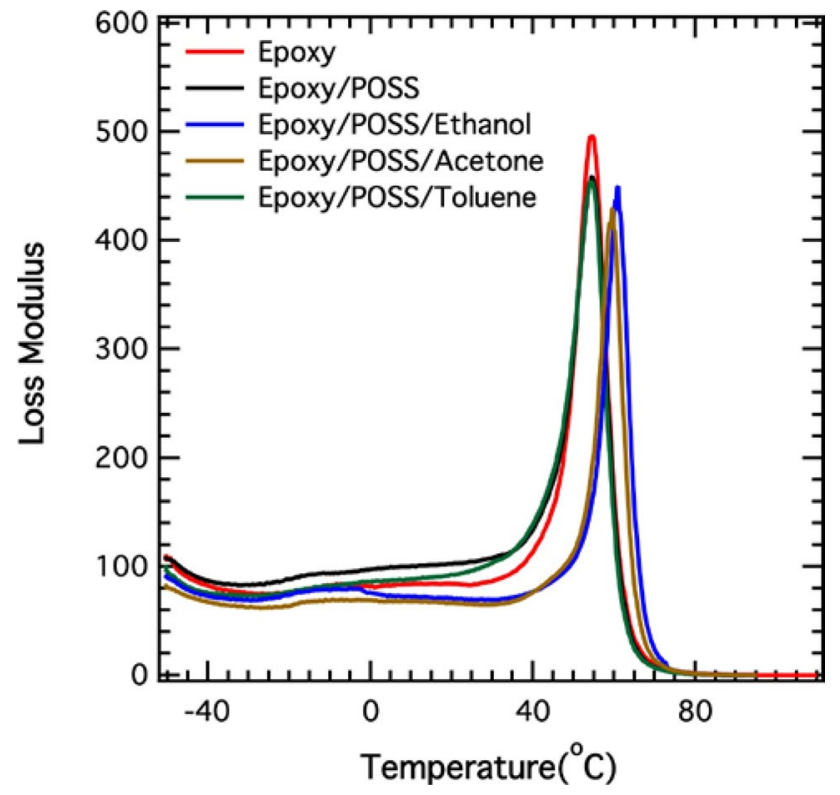

Fig. 5 Loss modulus curve of neat resin and 5 wt\% POSS/epoxy nanocomposite fabricated by different dispersion technique

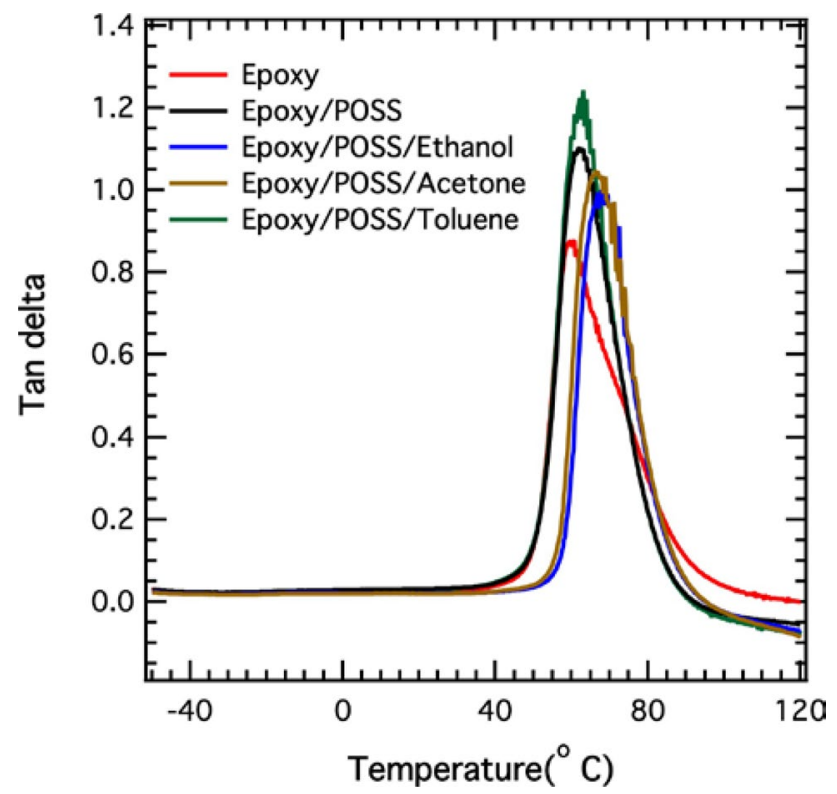

Fig. 6 Tan delta curve of neat resin and 5 wt\% POSS/epoxy nanocomposite fabricated by different dispersion technique

dispersion of POSS molecule we increase in the value of loss modulus (Fig. 5).

The damping ratio between storage and loss modulus is represented by tan delta. The peak of tan delta represents the glass transition temperature. Figure 6 illustrates that in the presence of solvent the dispersion of POSS increase which results in resistance against the motion of the
Table 1 Glass transition temperature, obtained from tan delta peaks, of neat resin and 5 wt\% POSS/epoxy nanocomposite fabricated using different solvents

\begin{tabular}{ll}
\hline Sample & $\begin{array}{l}\text { Glass transition } \\
\text { temperature }\left({ }^{\circ} \mathrm{C}\right)\end{array}$ \\
\hline Neat epoxy & $55.24 \pm 0.03$ \\
Epoxy with TSP POSS & $56.86 \pm 0.06$ \\
Epoxy with TSP POSS and ethanol & $63.33 \pm 0.14$ \\
Epoxy with TSP POSS and acetone & $58.19 \pm 0.11$ \\
Epoxy with TSP POSS and toluene & $61.31 \pm 0.09$ \\
\hline
\end{tabular}

Table 2 Glass transition temperature, obtained from tan delta peaks, of neat resin and 5 wt\% POSS/epoxy nanocomposite fabricated using different solvents

\begin{tabular}{lc}
\hline Sample & $\begin{array}{l}\text { Glass transition } \\
\text { temperature }\left({ }^{\circ} \mathrm{C}\right)\end{array}$ \\
\hline Neat epoxy & $40.17 \pm 0.01$ \\
Epoxy with TSP POSS & $41.18 \pm 0.05$ \\
Epoxy with TSP POSS and ethanol & $44.48 \pm 0.11$ \\
Epoxy with TSP POSS and acetone & $43.33 \pm 0.11$ \\
Epoxy with TSP POSS and toluene & $44.08 \pm 0.89$ \\
\hline
\end{tabular}

polymer chain hence increases the glass transition temperature as shown in Table 1. As discussed in the previous section, the presence of solvent enhances the dispersion of the POSS molecule in the epoxy resin. Better dispersion of POSS molecule in polymer network restrict the chain motion with the increase in temperature hence it increases the glass transition temperature as observer in Table 1.

\subsection{Differential scanning calorimetry (DSC)}

The results obtained from DMA were further confirmed by DSC results as given in Table 2. DSC result also, the addition of Trisilanol phenyl POSS in epoxy has increased the glass transition temperature. The presence of better dispersed POSS shows the increase in the glass transition temperature which is due to the obstruction in the movement of the polymer chain as discussed in DMA section. In case of epoxy/POSS/toluene, the presence of bigger benzene rings leads to the steric hindrance at some location in the polymer network hence more variation in the glass transition temperature observed.

\subsection{Scanning electron microscope (SEM) images}

Micrographs of the fractured surfaces are shown in Fig. 7. Figure $7 \mathrm{a}$ shows the featureless surface for the neat epoxy resin which indicates the lower resistance against crack propagation. For epoxy/POSS nanocomposite we observed no phase separation which indicates the 

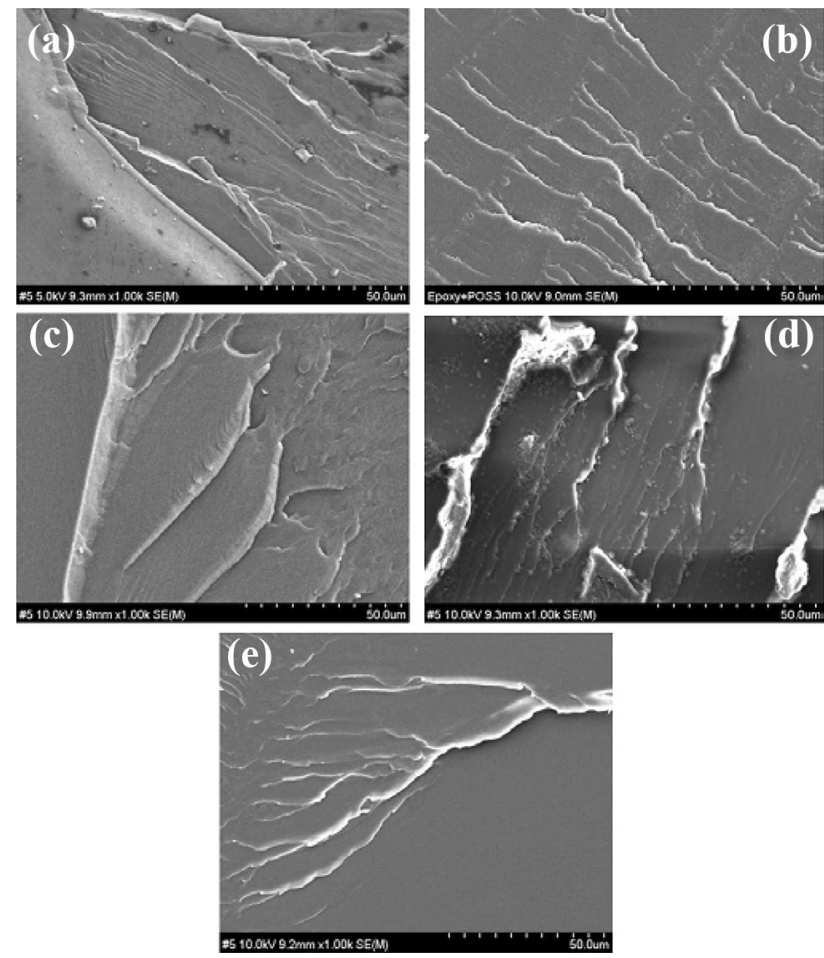

Fig. 7 Fractured morphology of a neat epoxy, b epoxy/POSS, c epoxy/POSS/ethanol, d epoxy/POSS/acetone, e epoxy/POSS/toluene

excellent dispersion of POSS in epoxy resin. We observe that the surface gets rough with the inclusion of POSS. These rough surfaces indicate greater resistance against crack propagation that contributes towards the enhancement of fracture toughness. In all images, the presence of rivermark indicate the phenomena of crack arrest and release suggests that the presence of POSS molecule directs the crack into a tortuous path.

\section{Conclusion}

In this work, three different solvents were used to disperse POSS in the epoxy resin and its influence on the mechanical and thermal properties. It was observed that the inclusion of POSS increases the fracture toughness of the nanocomposites. Fracture toughness result showed that better dispersion of POSS leads to a higher increase in fracture toughness. POSS dispersed by ethanol shows an increase by $80 \%$ at $5 \mathrm{wt} \%$ which is due to the polarity of ethanol that leads to better dispersion. However, nanocomposite prepared by toluene dispersion does not change the fracture toughness due to the formation of agglomerates.

Elastic modulus data showed that with the inclusion of POSS molecule the elastic modulus increases. For the epoxy/POSS nanocomposites prepared without any solvent shows an increase by $14 \%$ at $5 \mathrm{wt} \%$. The nanocomposite prepared by POSS dispersion due to ethanol shows a rise of $25 \%$ at $5 \mathrm{wt} \%$. The nanocomposite prepared by other solvent exhibits an increase of around $20 \%$. FTIR data indicates POSS form covalent bond between POSS and the epoxy resin as well as peak of constitutive solvent was not observed suggested that the solvent evaporated while mixing the solution.

The better dispersion of the POSS, based on the constitutive solvent, also shows an increase in the storage modulus, loss modulus, tan delta peak, and glass transition temperature. Scanning electron microscopy was used to observe the fractured surface of nanocomposites after fracture experiment. Presence of crack pinning lines and river marks provided further evidence of extrinsic toughening mechanism.

Acknowledgements This research was funded by NASA Experimental Program to Stimulate Competitive Research (EPSCOR) Grant Number NNX09AP68A.

\section{Compliance with ethical standards}

Conflict of interest The authors declare that they have no conflict of interest.

\section{References}

1. Bagheri R, Pearson R (1996) Role of particle cavitation in rubbertoughened epoxies. Polymer 37:4529-4538

2. Wetzel B, Rosso P, Haupert F, Friedrich K (2006) Epoxy nanocomposites: fracture and toughening mechanisms. Eng Fract Mech 73:2375-2398

3. Zunjarrao SC, Singh RP (2006) Characterization of the fracture behavior of epoxy reinforced with nanometer and micrometer sized aluminum particles. Compos Sci Technol 66:2296-2305

4. Qi B, Zhang QX, Bannister M, Mai YW (2006) Investigation of the mechanical properties of DGEBA-based epoxy resin with nanoclay additives. Compos Struct 75:514-519

5. Marouf BT, Bagheri R, Pearson RA (2008) Mechanical and thermal properties of montmorillonite-epoxy nanocomposite. Int J Mod Phys B 22:3247-3253

6. Zunjarrao SC, Sriraman R, Singh RP (2006) Effect of processing parameters and clay volume fraction on the mechanical properties of epoxy-clay nanocomposites. J Mater Sci 41:2219-2228

7. Seyhan AT, Sun Z, Deitzel J, Tanoglu M, Heider D (2009) Cure kinetics of vapor grown carbon nanofiber (VGCNF) modified epoxy resin suspensions and fracture toughness of their resulting nanocomposites. Mater Chem Phys 118:234-242

8. Rangari VK, Bhuyan MS, Jeelani S (2010) Microwave processing and characterization of EPON 862/CNT nanocomposites. Mater Sci Eng B Adv Funct Solid-State Mater 168:117-121

9. Mishra K, Singh RP (2019) Effect of APTMS modification on multiwall carbon nanotube reinforced epoxy nanocomposites. Compos Part B Eng 162:425-432

10. Rafiee MA, Rafiee J, Wang Z, Song HH, Yu ZZ, Koratkar N (2009) Enhanced mechanical properties of nanocomposites at low graphene content. ACS Nano 3:3884-3890

\section{SN Applied Sciences


11. Ruiz-Perez L, Royston GJ, Fairclough JPA, Ryan AJ (2008) Toughening by nanostructure. Polymer 49:4475-4488

12. Hydro RM, Pearson RA (2007) Epoxies toughened with triblock copolymers. J Polym Sci Part B Polym Phys 45:1470-1481

13. Goyat MS, Ray S, Ghosh PK (2011) Innovative application of ultrasonic mixing to produce homogeneously mixed nanoparticulate-epoxy composite of improved physical properties. Compos A 42:1421-1431

14. Ehsani M, Khonakdar HA, Ghadami A (2012) Assessment of morphological, thermal, and viscoelastic properties of epoxy vinylester coating composites: role of glass flake and mixing method. Prog Org Coat 76:238-243

15. Katnam KB, Stevenson JPJ, Stanleym WF, Buggy M, Young TM (2011) Tensile strength of two-part epoxy paste adhesives: influence of mixing technique and micro-void formation. Int J Adhes Adhes 31:666-673

16. Mishra K, Singh RP (2017) Quantitative evaluation of the effect of dispersion techniques on the mechanical properties of polyhedral oligomeric silsesquioxane (POSS)-epoxy nanocomposites. Polym Compos 39:E2445-E2453

17. Babu LK, Mishra K, Hamim SU, Singh RP (2018) Effect of excess silane on the viscoelastic behavior of epoxy under hygrothermal conditions. Int J Adhes Adhes 84:80-85

18. Ni CH, Ni GF, Zhang SW, Liu XY, Chen MQ, Liu LH (2010) The preparation of inorganic/organic hybrid nanomaterials containing silsesquioxane and its reinforcement for an epoxy resin network. Colloid Polym Sci 288:469-477

19. Sanchez-Soto M, Schiraldi DA, Illescas S (2009) Study of the morphology and properties of melt-mixed polycarbonate-poss nanocomposites. Eur Polym J 45:341-352

20. Fu BX, Hsiao BS, White H, Rafailovich M, Mather PT, Jeon HG, Phillips S, Lichtenhan JD, Schwab JJ (2000) Nanoscale reinforcement of polyhedral oligomeric silsesquioxane (POSS) in polyurethane elastomer. Polymer 49:437-440

21. Mather PT, Jeon HG, Romo-Uribe A, Haddad TS, Lichtenhan JD (1999) Mechanical relaxation and microstructure of poly(norbornyl-POSS) copolymers. Macromolecules 32:1194-1203

22. Schwab JJ, Lichtenhan JD (1998) Polyhedral oligomeric silsesquioxane (POSS)-based polymers. Appl Organomet Chem 12:707-713

23. Lichtenhan JD (1995) Polyhedral oligomeric silsesquioxanes building blocks for silsesquioxane-based polymers and hybrid materials. Comments Inorg Chem 17:115-130
24. Song L, He QL, Hu Y, Chen H, Liu L (2008) Study on thermal degradation and combustion behaviors of PC/POSS hybrids. Polym Degrad Stab 93:627-639

25. Leu CM, Chang YT, Wei KH (2003) Synthesis and dielectric properties of polyimide-tethered polyhedral oligomeric silsesquioxane (POSS) nanocomposites via POSS-diamine. Macromolecules 24:9122-9127

26. Knischka R, Dietsche $F$, Hanselmann R, Frey $H$, Mulhaupt $R$, Lutz PJ (1999) Silsesquioxane-based amphiphiles. Langmuir 15:4752-4756

27. Zheng L, Hong S, Cardoen G, Burgaz E, Gido SP, Coughlin EB (2004) Polymer nano-composites through controlled selfassembly of cubic silsesquioxane scaffolds. Macromolecules 37:8606-8611

28. Lin WJ, Chen WC (2004) Synthesis and characterization of polyimide/oligomeric methylsilsesquioxane hybrid films. Polym Int 53:1245-1252

29. Kopesky ET, Timothy SH, Mckinley GH, Cohen RE (2005) Miscibility and viscoelastic properties of acrylic POSS-PMMA blends. Polymer 46:4743-4752

30. Mishra K, Pandey G, Singh RP (2017) Enhancing the mechanical properties of an epoxy resin using polyhedral oligomeric silsesquioxane (POSS) as nano-reinforcement. Polym Test 62:210-218

31. Mishra K, Gidley D, Singh RP (2019) Influence of self-assembled compliant domains on the polymer network and mechanical properties of POSS-epoxy nanocomposites under cryogenic conditions. Eur Polym J. https://doi.org/10.1016/j.eurpo lymj.2019.02.034

32. ASTM D5045-14 (2014) Standard test methods for plane-strain fracture toughness and strain energy release rate of plastic materials. ASTM International, West Conshohocken

33. ASTM D638-14 (2014) Standard test method for tensile properties of Plastics. ASTM International, West Conshohocken

Publisher's Note Springer Nature remains neutral with regard to jurisdictional claims in published maps and institutional affiliations. 